\title{
FICCIÓN INMUNITARIA Y FALSA CONCIENCIA. SOBRE "MEN AGAINST FIRE" DE BLACK MIRROR
}

\author{
Immunity fiction and false consciousness. On Black Mirror's "Men Against \\ Fire"
}

\author{
David Becerra Mayor* \\ * Université catholique de Louvain (Bélgica) \\ david.becerra@yahoo.es
}

Palabras clave
Ficción
inmunitaria
Falsa conciencia
Ideología
Black Mirror
Deshumanización

\section{Keywords}

Immunity fiction

False

consciousness

Ideology

Black Mirror

Dehumanization

\begin{abstract}
Resumen
El objetivo de este artículo es analizar el capítulo "Men Against Fire" de Black Mirror, la serie británica emitida en Netflix, mediante el uso de dos herramientas teóricas y críticas como son la noción de "ficción inmunitaria" de Roberto Esposito y de "falsa conciencia" como primera definición de ideología producida dentro de la tradición marxista. Ambientada en un lugar y en un tiempo sin determinar, aunque posiblemente en un futuro no demasiado lejano, "Men Agaist Fire" trata de una comunidad que necesita inmunizarse ante la presencia de unos individuos que, estigmatizados como enfermos, pueden desestabilizar la comunidad por medio del contagio y poner en riesgo la supervivencia de la comunidad. Hay que levantar una frontera inmunitaria para salvar la especie, construir una ficción o una falsa conciencia que actúe como un muro que impida la entrada de esos individuos en la comunidad. Construir un otro que evidencie que ellos no son como nosotros. Este artículo tratará de mostrar el modo en que la construcción del otro como sujeto deshumanizado no solamente funciona como un relato construido al servicio de la protección de la comunidad, sino también como una forma de producir indiferencia y de este modo suspender las reacciones morales por parte de quien aprieta el gatillo en la guerra para aniquilar al enemigo. Frente a este discurso construido por quienes están en el poder, se plantea la necesidad de reivindicar la noción de verdad como instrumento para combatir las ficciones del poder.
\end{abstract}

\section{$\underline{\text { Abstract }}$}

The main objective of this article is to analyze the episode entitled "Men Against Fire" of Black Mirror, the UK series broadcasted in Netflix, through two theoretical and critical tools: "immunity fiction" by Roberto Esposito and "false consciousness" as the first definition of "ideology" produced inside the Marxist tradition. Set in an unspecific place and time, probably in the not too distant future, "Men Against Fire" dealing with a community that needs to immunize from individuals who, stigmatized as sick, could disrupt the community spreading their infection and even could threat the existence of the community. They must build an immunity border to save the species, to build a fiction or a false consciousness acting as a wall to avoid the entrance of those individuals into the community. They must build an otherness evidencing they are not as us. This article seek to show the way by which the construction of the other as a dehumanized subject not only works as a narrative built to protect the community, but also to produce indifference and, thus, to prevent the moral reactions by those who pulls the trigger during the war to destroy the enemy. In order to oppose the narrative of those in power, it claims the notion of truth as an instrument to fight against the fictions of the power.

Becerra Mayor, D. (2018). Ficción inmunitaria y falsa conciencia. Sobre "Men Against Fire" de Black Mirror. Papeles del CEIC. International Journal on Collective Identity Research, vol. 2018/1, papel 189, CEIC (Centro de Estudios sobre la Identidad Colectiva), UPV/EHU Press, http://dx.doi.org/10.1387/pceic.18873 


\section{INTRODUCCIÓN ${ }^{1}$}

No hay cronotopo. No sabemos exactamente cuándo sucede ni dónde sucede. Simplemente observamos a un ejército que, urgentemente, abandona la base militar para desplazarse a un poblado donde, según parece, se ha producido un robo. Cuentan que han sido de nuevo las cucarachas (roaches). A partir de esta primera escena el espectador puede intuir que las denominadas cucarachas conforman una guerrilla que perturba y pone en peligro el orden establecido. Todo parece indicar que las cucarachas actúan como maquis: se refugian en el monte, pero bajan con frecuencia a los poblados para robar comida y abastecerse de provisiones. El ejército tiene que intervenir para que la región recupere la calma y todo regrese, lo más pronto posible, a la normalidad. Así arranca "Men Against Fire", quinto capítulo de la tercera temporada de Black Mirror -la serie creada por Charlie Brooker-, que fue estrenado en Netflix el 21 de octubre de 2016.

Black Mirror, más allá de ser una obra de entretenimiento, es una serie que ha explorado, a través de ficciones ubicadas en futuros no demasiado lejanos, los efectos nocivos que tiene, o podría llegar a tener, la tecnología sobre nuestra vida. Black Mirror muestra el modo en que los avances tecnológicos no funcionan como una tecnología del yo, esto es, como un dispositivo que le permite al sujeto realizar su individualidad de forma plena y autónoma, o

"(...) efectuar, solos o con la ayuda de otros, un cierto número de operaciones sobre su cuerpo y su alma, sus pensamientos, sus conductas, su modo de ser; es decir, de transformarse con el propósito de alcanzar un cierto estado de alegría, felicidad, pureza, sabiduría, perfección o inmortalidad" (Foucault, 1994b: 785) $)^{2}$

sino como un dispositivo biopolítico que finalmente disciplina al individuo y reprime la posibilidad de anunciar su subjetividad (Foucault, 2009a).

Para ello, Black Mirror toma plataformas o redes sociales hoy existentes y exagera su funcionamiento, llevándolo al extremo, para escenificar cómo, lejos de liberar nuestra subjetividad, esas herramientas terminan

\footnotetext{
${ }^{1}$ Este trabajo se ha realizado con la ayuda del programa internacional de investigación "Move-in Louvain. Incoming post-doc Fellowship" de la Université catholique de Louvain.

${ }^{2}$ Todas las citas, tanto las que proceden de la serie analizada como del aparato crítico y teórico, han sido traducidas por el autor.
} 
secuestrando nuestra libertad. Constituye un claro ejemplo el primer capítulo de la tercera temporada, titulado "Nosedive", en el cual se muestra cómo el "capital simbólico" (Bourdieu, 1994: 161) de los ciudadanos - convertidos en usuarios por una red social que recuerda sobremanera a Instagram, pero también a los métodos de evaluación de las plataformas de consumo como Deliveroo o Uber- depende de las evaluaciones del resto de usuarios, hechas tras cada encuentro. Lo que tendría que liberar al individuo termina reprimiendo la subjetividad, siempre sujeta a $-y$ condicionada por- la opinión de los demás usuarios. Nadie puede ser como realmente es, o quiere ser, sino que actúa en función de quienes lo puntúan. Del mismo modo, en "The Entire History of You", el capítulo con el que cierra la breve primera temporada -compuesta únicamente de tres capítulos-, los personajes tienen implantado detrás de la oreja un dispositivo con el que registran toda su vida, lo que les permite fijar recuerdos y rememorarlos cuando lo deseen; pero los personaje terminarán siendo dependientes de ese pasado del que no logran liberarse y toda experiencia presente se verá salpicada por unos recuerdos imborrables, siempre disponibles para ser revisitados. También ocurre en capítulos más recientes, como en el de la cuarta temporada, "Hang the DJ", cuya trama se construye sobre una aplicación de búsqueda de pareja que elige por el usuario a su pareja ideal tras combinar algoritmos que analizan la compatibilidad de los caracteres; o en "Arkangel", también de la cuarta temporada, donde una aplicación le permite a una madre observar, para protegerla, todo lo que hace su hija, quien, al hacerse mayor, comprueba que el precio de su seguridad ha sido la pérdida de su intimidad.

Black Mirror plantea, en buena parte de sus capítulos, los efectos de la tecnología sobre nuestro cuerpo e intimidad, el modo en que la tecnología, en vez de cumplir su promesa de liberar al sujeto, constituye finalmente un dispositivo de control. No en vano la serie invita a ser analizada desde distintas perspectivas filosóficas o sociológicas, sea desde los "imaginarios sociales de la democracia" o los "imaginarios del castigo" (Cigüela Sola y Martínez Lucena, 2014a y 2014b), desde una crítica de la sociedad del espectáculo y el papel que desarrollan en la virtualización de la realidad los medios de comunicación (Díaz Gandasegui Correo, 2014) o en la aplicación de las tecnologías de vigilancia y de control social (Hernández-Santolla y Hermida, 2016; Barraycoa Martínez, 2012). 
"Men Agaist Fire", que es el episodio que nos ocupa, muestra la relación entre los avances tecnológicos y su aplicación en un contexto de guerra. El capítulo toma su título del libro de un general de la Segunda Guerra Mundial, S. L. A. Marshall, igualmente titulado Men Against Fire: The Problem of Battle Command (1947). En su libro, el general declara, según Wikipedia, que "durante la Segunda Guerra Mundial, el $75 \%$ de los soldados no disparaba sus rifles, ni siquiera bajo una amenaza inmediata, $y$, de hecho, la mayoría de ellos, cuando lo hacía, apuntaba por encima de la cabeza del enemigo" ("Men Against..."). El episodio que nos disponemos a analizar explica los motivos por los cuales esto sucedía en el pasado y asimismo plantea el modo en que sería posible evitarlo a través del uso de la tecnología de guerra, mediante la aplicación de un dispositivo capaz de superar los límites que sobre el ser humano tiene la propaganda de guerra.

\section{LA DESHUMANIZACIÓN DEL ENEMIGO Y LA FICCIÓN INMUNITARIA}

En la primera escena, y en la denominación temprana del enemigo como cucaracha, se enuncia ya uno de los principios básicos de la propaganda de guerra. La historiadora belga Anne Morelli, en un libro titulado precisamente Principes élémentaires de propagande de guerre (2001), recoge, en una suerte de decálogo, las narrativas que se activan durante los conflictos bélicos para legitimar los actos de guerra y de violencia. Varios de estos principios elementales de la propaganda de guerra están presentes en el capítulo "Men Against Fire" de Black Mirror, pero el que se muestra de forma más transparente acaso sea el tercer punto de la lista confeccionada por Morelli: "El enemigo tiene la cara del diablo" (ibídem: 21-26). El enemigo es la encarnación del mal $y$, en consecuencia, carece de rasgos humanos. Hay una deshumanización del enemigo que, en el caso de "Men Against Fire", se lleva a cabo por medio de su animalización: el apelativo cucaracha es un modo de restarle -o de negarle- humanidad a estos individuos. La deshumanización/animalización del enemigo funciona como estrategia ideológica de construcción de la otredad. Con ello, se traza una línea clara que divide y distingue entre nosotros, los miembros de una comunidad que viven -o pretenden vivir- de forma apacible en el interior de esta, y los otros que, desde un exterior amenazante y desestabilizador, ponen en peligro a la comunidad. Este principio elemental de la propaganda de guerra funciona, pues, como una ficción 
inmunitaria que la comunidad construye para protegerse de ese otro construido como enemigo.

Pero antes de entender cómo -y por qué- se construye ese otro y qué elementos integran esa ficción inmunitaria, conviene saber qué tipo de conflicto bélico está representado en este capítulo de Black Mirror. A partir de la lectura del ensayo de Enzo Traverso 1914-1945. La guerre civile européenne (2009), es posible distinguir entre dos formas de hacer la guerra: por un lado, la guerra entre Estados "civilizados" que enfrenta a "enemigos legítimos" $y$, por otro, las guerras coloniales que inspirarian las guerras totales del siglo XX. En las guerras del primer tipo, donde "sus herramientas mentales y sus referencias culturales permanecen vinculadas a la experiencia europea del siglo XIX, con sus guerras 'civilizadas' (...) los combatientes se respetan como adversarios legítimos" (ibídem: 89). La guerra, que enfrenta a dos Estados que se reconocen como civilizados, tiene unas normas claras: los Estados enfrentados firman una suerte de pacto entre caballeros que los lleva a combatir y a actuar dentro de un marco legal donde los actos de guerra deben respetar unos códigos de respeto y honor. No todo vale. En la guerra colonial, sin embargo, el adversario no es ni legítimo ni respetable. Difuminada la humanidad del enemigo y dibujado como exponente de la barbarie, la civilización se arroga el derecho a conquistar sus territorios. A cualquier precio, sin códigos ni normas ni pactos entre caballeros. En este caso, la masacre y la aniquilación total están permitidas. No hay dos fuerzas que luchen en un mismo plano de igualdad, sino una civilización que se impone $-\mathrm{y}$ se erige con el derecho de imponerse- sobre la barbarie. Sobre esta dialéctica civilización/barbarie se construye la idea de la guerra justa: todo es válido en nombre de una civilización que, para avanzar, debe eliminar todo resquicio de barbarie que se ponga en el camino de la civilización. De este modo lo expone Enzo Traverso:

"(...) al concebirse el mundo no europeo como un espacio colonizable, las guerras de conquista e incluso las masacres coloniales se transformaron ipso facto en "guerras justas" en el nombre del derecho natural (de comercio, de circulación y de propiedad, es decir, de apropiación de tierras y de bienes que supuestamente no pertenecian a nadie). Concebidas como empresas de conquista ( $y$, a menudo, de exterminio), en las que los ejércitos europeos no se enfrentaban a otros ejércitos regulares sino a tribus y a combatientes sin un estatus bien definido desde el punto de vista de los 
conquistadores, las guerras coloniales no hacian ninguna distinción entre soldados y civiles. En este sentido, las masacres que acompañaron la historia del colonialismo constituyeron un modelo para las guerras totales del siglo $\mathrm{XX}$ (ibídem: 90).

"Men Against Fire" pone en escena este segundo tipo de guerra”. En primer lugar, se observa, cuando el ejército llega al poblado que ha sido asaltado, que los pobladores autóctonos y los soldados no hablan el mismo idioma. Para entenderse utilizan un aparato de traducción simultánea. Podemos colegir, pues, que se trata de un ejército de ocupación. En segundo lugar, no se enfrentan a un ejército regular sino a lo que en apariencia es una tribu que no se ha integrado en el nuevo orden impuesto por las fuerzas coloniales y, en consecuencia, resisten y combaten por medio de la estrategia de la guerra de guerrillas. En tercer -y último- lugar, en esta guerra de ocupación cada vez aparece más difuminada la línea que separa a los soldados y a los civiles. En una de las escenas cruciales se muestra la fragilidad de esta línea. En la escena, las fuerzas coloniales - creo que ya podemos denominarlas así- se adentran en una casa en la que habita un hombre con un hondo sentimiento religioso y humanista. Mientras el resto de los soldados va a peinar las distintas estancias de la casa, sospechando que en ellas se encuentran cucarachas escondidas, Medina, la militar que dirige el grupo, acusa al hombre de colaboracionista y lo induce a abandonar su empeño humanista de proteger a las cucarachas, reproduciendo los puntos clave de esa ficción inmunitaria que deshumaniza al enemigo y

\footnotetext{
${ }^{3}$ Claro que en este capítulo de Black Mirror nunca va a aparecer el verdadero móvil de la guerra, esto es, la apropiación de tierras, bienes o recursos. Esta borradura de la materialidad, o de las causas materiales que propician el conflicto, es común a muchos de los relatos postapocalípticos en series televisivas. Resulta interesante, por poner solo un ejemplo, observar cómo en The Walking Dead los conflictos que se desencadenan en las distintas temporadas nunca están motivados, salvo tangencialmente a partir de la sexta temporada -o sea, cuando ya está muy avanzada la serie-, por la falta de recursos por los cuales los distintos grupos en disputa tienen que competir. Ese conflicto radical, verdaderamente político y social, desaparece y se desplaza a favor de la representación de un conflicto basado en la idea del mal: los antagonistas lo son porque encarnan un ideal abstracto de mal, no porque tengan que competir con los protagonistas por unos recursos que son sin duda escasos en ese mundo postapocaliptico dominado por los zombis llamados caminantes (walkers). Este desplazamiento del conflicto radical por otros discursos asumibles (como en este caso es la abstracción del mal) es constitutivo del discurso narrativo neoliberal, como he estudiado, a partir del análisis de la novela española actual, en La novela de la no-ideología (Becerra Mayor, 2013).
} 
que alerta de los riesgos que supone su existencia para la inmunidad de la comunidad. Este es su parlamento:

Tienes principios. Piensas que toda vida es sagrada. Te entiendo. Estoy de acuerdo. Toda vida es sagrada... por eso incluso proteges a las cucarachas, ¿verdad? No es su culpa que sean así. Ellas no pidieron ser así. Te entiendo. Nosotros lo entendemos. Es esa mierda que tienen en la sangre lo que las hace así. A ellas no les importa lo sagrado de la vida o el dolor de quienes sufren. Si no acabamos con las cucarachas, dentro de cinco, diez, veinte años, nacerán niños con la misma enfermedad, que luego se reproducirán. Y seguirá el ciclo del dolor, la enfermedad..., aunque todo podría haberse evitado. Por cada cucaracha que salvas hoy, estás condenando a sabe Dios cuánta gente a la desesperación y a la miseria mañana. No puedes seguir viéndolas como humanos. Es un sentimiento comprensible, de acuerdo, pero equivocado. Tenemos que eliminarlas si queremos que la humanidad siga en este mundo. Esta es la dura verdad. Tenemos que hacer sacrificios.

En este discurso se conjugan dos de las ideas clave de este capítulo: la deshumanización del enemigo y la ficción inmunitaria. Los principios humanistas les otorgan valor a todas las vidas humanas —“la vida humana es sagrada", afirma-, incluso a las vidas de los despreciables enemigos. Pero este discurso humanista puede poner en riesgo a la humanidad entera. Por eso es tan importante construir la otredad y llevar a cabo una deshumanización del enemigo que evite cualquier posibilidad de empatía. No hay que verlos como nosotros sino como el peligro que pone en riesgo precisamente la existencia de ese nosotros. La sangre de las cucarachas está infectada y, si se mezcla con la nuestra, puede hacer que nuestra comunidad enferme. Para que la comunidad sobreviva debe aniquilar a las cucarachas, hacer desaparecer al enemigo de la faz de la tierra. Esta es la "dura verdad" biopolítica: la supervivencia de la comunidad pasa por "sacrificar a las cucarachas". Sin embargo, esta "dura verdad" no es sino una ficción construida sobre lo que Roberto Esposito denomina "paradigma inmunitario" en su Inmunitas. Protección y negación de la vida (2015):

"Ya sea el asediado el cuerpo de un individuo, por una enfermedad propagada; el cuerpo político, por una intromisión violenta; o el cuerpo electrónico, por parte de un mensaje aberrante, lo que permanece invariado es el lugar en el cual se sitúa la amenaza, que es siempre el de la frontera 
entre el interior y el exterior, lo propio y lo extraño, lo individual y lo común. Alguien o algo penetra en un cuerpo individual o colectivo-y lo altera, lo transforma, lo corrompe. El término que mejor se presta a representar esta mecánica disolutiva - justamente por su polivalencia semántica, que lo ubica en el cruce entre los lenguajes de la biología, el derecho, la política y la comunicación- es contagio. Lo que antes era sano, seguro, idéntico a sí mismo, ahora está expuesto a una contaminación que lo pone en riesgo de ser devastado" (ibídem: 10).

La comunidad, expuesta al contagio, debe defenderse para garantizar su supervivencia. Toda violencia será legítima, incluso las prácticas de la guerra total. No es descabellado pensar que en "Men Against Fire" se haya llegado a suspender el derecho y que más bien se aplique el estado de excepción en la acepción propuesta por Giorgio Agamben en Homo Sacer: una suspensión del orden jurídico que, si bien en un principio se promulga como una medida de carácter provisional, acaba constituyéndose como forma de gobierno; $y$, en consecuencia, la violencia por parte del Estado nunca será juzgada. La excepcionalidad se hace norma (Agamben, 1998: 57). El hecho de que esta escena termine, una vez que los soldados hayan descubierto la presencia de cucarachas en la casa, con el secuestro - $y$, es fácil imaginar, su posterior tortura y asesinato- de un civil, muestra hasta qué punto, en tales condiciones, todo está permitido. La distinción entre soldado y civil, propia de las "guerras civilizadas", se difumina: todos son potenciales enemigos y, llegado el caso, si es preciso, también los civiles serán aniquilados si su actitud, aunque sea pasivamente, pone en riesgo la inmunidad de la comunidad.

La escena que acabamos de contemplar representa la primera "caceria" -así denominada, en el argot militar del capítulo, para potenciar sin duda la deshumanización/animalización del enemigo- de Stripe Koinange, el protagonista de "Men Against Fire". Stripe se hace llamar por su nombre de pila, no por su apellido, impronunciable para sus camaradas de las fuerzas de ocupación. Este hecho denota que Stripe no ha llegado al lugar con el resto de las fuerzas coloniales, sino que es un autóctono reclutado. Stripe encarna a esos jóvenes sin vocación, esperanza o expectativas que se enrolan en el ejército ante la ausencia de un horizonte de prosperidad y bienestar (lo descubriremos al final del capítulo mediante un flashback). 
En su primera cacería, Stripe verá por primera vez a las cucarachas. El espectador también las verá por primera vez, a través de los ojos del recluta. En efecto, no son como nosotros; más bien son como monstruos. No se aprecia humanidad en sus rostros. La tensión dramática de la escena llega a su máximo punto cuando Stripe se ve con serias dificultades para deshacerse de uno de los enemigos, con quien mantendrá un combate cuerpo a cuerpo, hasta que finalmente logre matarlo apuñalándolo repetidas veces en el corazón. En el transcurso del combate, la cucaracha había sacado un dispositivo, aparentemente inofensivo, que emitía una luz verde. Lo único que hizo fue mostrárselo al soldado, ponerlo delante de sus ojos.

De vuelta a la base, Stripe empieza a sentirse mal. No duerme bien -sus sueños eróticos, que más tarde descubriremos que están programados por quienes detentan el poder (y esto es una primera muestra de cómo el poder ha colonizado también las conciencias), han perdido la lógica narrativa que hasta el momento tenían-, se marea, percibe sonidos que antes no percibía y, en los campos de entrenamiento, comprueba que le falla la puntería. Visita al médico que, al no detectarle ninguna dolencia física, le recomienda que visite al psicólogo para evaluar si sufre algún trastorno post-traumático. Arquette, así se llama el psicólogo, le pide que le cuente su enfrentamiento con la cucaracha. Lo primero que le llama la atención -e indudablemente le preocupa- a Arquette es la espontánea humanización que hace Stripe del enemigo por todos animalizado, cuando se refiere a él por medio del pronombre he, reservado en inglés a los sujetos humanos, en vez de it, relativo a las cosas $u$ otros sujetos sin humanidad:

Stripe: (...)él (he) estaba en el suelo conmigo.

Arquette: ¿Él? (He?)

Stripe: Eso era un él (It was a he).

Stripe, con su respuesta, parece excusarse: ha utilizado he no como oposición a it, sino como oposición a she. La elección de su pronombre no ha sido para marcar el género humano de la cucaracha -lo que sin duda preocupa a Arquette-, sino como marca de género masculino. En cualquier caso, para averiguar los motivos de esta humanización, Arquette lo interroga entonces sobre sus sentimientos, le pide que exprese qué sintió en su lucha cuerpo a cuerpo contra la cucaracha:

Arquette: $Y$, ¿qué sentiste?

Stripe: ¿Cómo...? 
Arquette: Emocionalmente.

Stripe: No sentí nada. Quiero decir, fue muy rápido. Fue un acto de defensa propia. Me sentí, supongo, aliviado.

Arquette: ¿Solo aliviado?

Stripe: U-uh.

Arquette: No es inusual experimentar otros sentimientos.

Euforia, incluso.

Stripe: Sí, supongo. No sé, quizá sentí, no sé...

Arquette: ¿Algo más?

Stripe: Sí, como...

Arquette: ¿Arrepentimiento?

Stripe: Algo así, pero ya no lo siento.

Arquette: Entonces, ¿lo volverías a hacer?

Stripe: Sí, claro.

Arquette: Entonces... ¿por qué estás aquí? [risas]

Los sentimientos de alivio y euforia son aceptables, pero no el arrepentimiento (regret). Aunque no se adelanta el diagnóstico, y la escena termina entre risas, tras asegurarse Arquette de que Stripe actuaría de la misma forma si se diera una situación similar, es posible interpretar que esa risa en verdad esconde una sospecha y una preocupación por parte del psicólogo. El arrepentimiento puede ser un indicativo de que una fisura se ha abierto en su conciencia.

\section{LA IDEOLOGÍA COMO FALSA CONCIENCIA}

Acaba de aparecer el tercer elemento clave: la conciencia. O mejor: la falsa conciencia. Una de las primeras definiciones que la tradición marxista ofreció para ideología no fue sino esa: falsa conciencia. En La ideología alemana de Karl Marx y Friedrich Engels (1958), la ideología funciona como un instrumento mediante el cual la clase dominante introduce el engaño en la conciencia del hombre para que actúe en función del orden social construido por esa clase dominante. La noción de "falsa conciencia" aparece intimamente ligada al concepto de alienación en tanto produce una visión del mundo errónea y desligada de la realidad material. Marx y Engels apuntan que esa falsa conciencia ha conducido a los hombres a formarse "ideas falsas acerca de sí mismos, acerca de los que son o debieran ser" (ibídem: 11). La ideología crea una ilusión, una falsa percepción de la realidad $y$, en tanto que falsa conciencia, dota a la realidad de una apariencia errónea que impide al hombre reconocerse tal cual es. De otra forma lo escribirá tiempo después Engels en una carta destinada a Franz Mehring: 
"La ideología es un proceso que se opera por el llamado pensador conscientemente, en efecto, pero con una conciencia falsa (...). Trabaja exclusivamente con material discursivo, que acepta sin mirarlo, como creación del pensamiento, sin someterlo a otro proceso de investigación, sin buscar otra fuente más alejada e independiente del pensamiento; para él, esto es la evidencia misma" (1974: 523).

Los aparatos ideológicos del Estado -si seguimos la terminología propuesta por Louis Althusser (2004: 115-155) - son utilizados para la creación de esa falsa conciencia que le hace percibir al individuo la realidad de forma distorsionada y, en función de ella, actuar en beneficio y según los intereses de la clase dominante ${ }^{4}$.

\footnotetext{
${ }^{4}$ Sin embargo, con esta definición no se agotan, dentro de la tradición marxista, los distintos intentos por definir y elaborar la noción de "ideología". La noción de "falsa conciencia" pertenece a la producción teórica del primer Marx (en colaboración con Engels), es decir, antes de que se produjera lo que Althusser denominó el "corte epistemológico" de Marx (Althusser, 1971: 27-28). Hasta este momento, Marx entendia, como se ha visto, la ideología como un dispositivo vertical que operaba desde la superestructura para modificar las conciencias de los seres humanos, que, alienados por las falsas ideas inoculadas en su conciencia por el poder, actuaban en contra de sus propios intereses. Pero, tras producirse la ruptura, la reflexión sobre la noción "ideología" desaparecerá de los textos de Marx (no hay una teoría de la ideología de forma explícita en El capital como sí la hubo en La ideología alemana), aunque, de forma acaso implícita, y siguiendo a Althusser, su ausencia no nos impide pensar que, en el fondo y sin nombrarla, Marx está reelaborando una teoría de la ideología en la cual esta ya no deriva de la superestructura sino que emerge de las mismas relaciones materiales. Es decir, la alienación no responde a la introducción de una ilusión en la conciencia del ser humano, sino que deriva de su reificación - su transformación en cosa, en objeto, esto es, en la negación de su subjetividad-que se da en el proceso productivo mismo. Cuando se inserta en el proceso de producción el sujeto ya está alienado, ya actúa obedeciendo no sus propios intereses sino los intereses de quien posee los medios de producción. No es necesario, pues, introducir ideas falsas en su cabeza: su inserción en un modo de producción específico lo mueve a actuar en función de él. Y, en consecuencia, según esta nueva concepción de la "ideología", la lucha ideológica no pasaría por la descodificación de la realidad, sino por la transformación de las relaciones materiales. Sin embargo, estas dos definiciones no son excluyentes, sino más bien complementarias, y han tenido un recorrido amplio dentro de la tradición marxista. Si la primera influyó sin duda a Antonio Gramsci en la conceptualización de la noción de "hegemonía" (2007, II: 1481-82, 14921493; III: 1518-19, 1577, 2011-2013), después reelaborada por teóricos postmarxistas como Ernesto Laclau o Chantal Mouffe (1987), la segunda fue clave en la definición althusseriana de "ideología" como "relación vivida de los hombres con el mundo", siempre de forma "inconsciente" e "imaginaria" (Althusser, 1970: 93-94), y más tarde redefinida por uno de sus discípulos más destacados, Juan Carlos Rodríguez, en su teoría del "inconsciente ideológico" (1991). Para hacer un recorrido más detallado por las distintas acepciones de "ideología" en el interior de la tradición marxista, véase mi introducción a La novela de la no-ideología (Becerra Mayor, 2013: 9-41) e igualmente Eagleton (1996) y Žižek (2004a).
} 
Stripe, nuestro protagonista, descubrirá en la siguiente escena cómo la ideología, en tanto falsa conciencia, funciona como una máscara que le impide ver la realidad tal cual es, como ese "material discursivo" que se acepta sin someterlo a la crítica, como si fuera la "evidencia misma". En su segunda cacería Stripe vuelve a sentir los mismos síntomas de malestar que experimentó al regresar de la primera cacería: mareos, percepción de ruidos y olores, interferencias en su escáner mental de lectura de mapas, etc. En las inmediaciones de un edificio de vivienda social y protegida (elemento que sin duda nos permite deducir que la guerra es asimismo una guerra de clases), los militares cruzan disparos con las cucarachas que se refugian en su interior. Desde el exterior, los soldados disparan sin distinguir los rostros del enemigo: se encuentran demasiado lejos. Stripe ingresa al edificio, acompañado ahora por Rai, una militar de su mismo rango. En el espacio cerrado, donde las distancias se reducen y el enfrentamiento cuerpo a cuerpo se hace de nuevo posible, podrían verse las caras con el enemigo, mirarse a los ojos. La mirada podría desactivar el relato deshumanizador; la mirada podría servir para que ambos enemigos se reconocieran, a pesar de todo, como iguales, y se perdonaran la vida, como ocurre en Soldados de Salamina de Javier Cercas (2001), cuando el soldado republicano mira a los ojos al falangista Sánchez Mazas y decide salvarle la vida ${ }^{5}$. Que esto ocurra debe evitarse a toda costa, ya que una simple mirada podría desestabilizar la comunidad.

Escenas de interior. Stripe recorre pasillos y habitaciones hasta que entra en un cuarto donde se encuentra a una mujer con un bate de béisbol. Stripe le dice que no va a hacerle daño, pero le recuerda que allí no va a estar a salvo, que el edificio está lleno de cucarachas. Cuando la mujer sale al pasillo, suena un disparo que termina con su vida. Ha sido Rai. Ella, a diferencia de Stripe, no ha visto a una mujer, ha visto una cucaracha. Tras varias escenas de disparos en las que Rai mata a todo aquel que se cruza por su camino, Stripe se encuentra en una habitación con una mujer y un niño. De nuevo, Stripe logra distinguir humanidad en sus rostros allí donde Rai no ve sino monstruos. En consecuencia, Rai quiere asesinarlos pero Stripe se lo impide y llega incluso a golpearla para proteger las vidas de las cucarachas. En el enfrentamiento, Stripe

\footnotetext{
${ }^{5}$ Para una problematización de esta construcción humanista de Soldados de Salamina y para estudiar sus efectos ideológicos, véase el análisis que le dedico en mi libro La Guerra Civil como moda literaria (Becerra Mayor, 2015: 246-250).
} 
queda herido por una bala, fortuitamente disparada. Las cucarachas conducen a Stripe a su refugio para curarlo. En esta escena fundamental se produce el siguiente diálogo que, aunque largo, conviene reproducir por entero:

Cucaracha: ¿Puedes verme como soy?

Stripe: Por supuesto, te veo.

Cucaracha: ¿No ves una cucaracha?

Stripe: Tú no eres una cucaracha. Las cucarachas son...

Cucaracha: ¿Horribles?

Stripe: Las cucarachas no hablan.

Cucaracha: Tú no podías oírnos.

Stripe: ¿De qué mierdas estás hablando?

Cucaracha: Tus implantes. Los implantes del ejército.

Stripe: ¿La máscara?

Cucaracha: Ellos la han puesto en tu cabeza para ayudarte a luchar y cuando funciona nos ves de otra manera. Uno de nosotros, Luka, ha fabricado una... una máquina. Emite destellos de luz. Decía que podría interferir con vuestro implante.

Stripe: ¿Eres una cucaracha? Pero yo he visto cucarachas. Las he visto... Son como...

Cucaracha: ¿Animales?

Stripe: No, son monstruos. Yo las he visto.

Cucaracha: El implante hace que las veas así.

Stripe acaba de entenderlo todo: los soldados llevan una máscara implantada que, como una falsa conciencia, les impide ver la realidad tal cual es. En consecuencia, los soldados no solo ven al enemigo como monstruos, sino que además tampoco pueden escucharlos. Hasta ahora Stripe no sabía que las cucarachas sabían hablar. No se puede humanizar al enemigo si este no puede ser mirado ni escuchado. Stripe descubre, a lo largo de la conversación, que su máscara sufre interferencias debido a que fue expuesta a la luz del dispositivo de la cucaracha durante su primera cacería. Sin embargo, hay algo que no encaja para Stripe: no solo los soldados odian a las cucarachas, sino también los pobladores locales, que no tiene máscaras instaladas en sus cabezas:

Stripe: Los del pueblo, ellos... no son del ejército. No tienen la máscara en sus cabezas. Tienen miedo a las cucarachas. Odian esas jodidas cosas.

Cucaracha: Todo el mundo nos odia.

Stripe: Entonces, ¿qué cojones ven ellos, eh? Los jodidos civiles, cuando ven a una cucaracha, ¿qué ven? 
Cucaracha: Lo que tú ves ahora. Ellos nos odian de todos modos, porque es lo que les han dicho. Hace diez años que esto empezó. Postguerra. Primero, los chequeos, los exámenes de ADN, luego el registro, las medidas de emergencia. Y pronto todo el mundo empezó a llamarnos criaturas. Criaturas inmundas. Cada voz, en la televisión, en el ordenador. Dicen que tenemos... que tenemos una enfermedad dentro. Que tenemos un punto débil, que es nuestra sangre. Dicen que nuestra sangre no puede existir. No podemos existir.

Los civiles también odian y temen a las cucarachas, aunque ellos vean seres humanos, como Stripe ahora, y no monstruos. A diferencia de los militares, la falsa conciencia de los civiles no está fabricada por medio de la tecnología de guerra, sino que sigue el modelo de manipulación tradicional: los aparatos ideológicos de Estado -la educación, la televisión, internet, etc.- reproducen diariamente la idea de que hay que odiar a las cucarachas, en tanto su enfermedad pone en riesgo de contagio a la comunidad, y ellos no hacen sino asumir el discurso del poder como normalidad.

En esta escena podemos apreciar cómo se reproduce lo que Žižek define como esa idea humanista y liberal que dice que "un enemigo es alguien cuya historia todavía no ha sido escuchada" (2012a: 47). Ahora que hemos escuchado su historia, comprendemos al enemigo, que aparece humanizado y subjetivizado. Tiene una historia y una vida que, aunque ponga en peligro a la comunidad, merece ser vivida. La culminación de la subjetivización/humanización se produce cuando se conocen sus nombres: "Mi nombre era Catarina, y él era Alec. Ahora solo somos cucarachas. Pero ahora... ahora puedes verme. Ahora puedes verme". y de nuevo la mirada: "ahora puedes verme". Al mirarse, se reconocen, se identifican, se rompe la línea que los construye como enemigos. Son exactamente iguales.

En este momento de máxima identificación y, en consecuencia, de compasión hacia el enemigo, Rai entra en el refugio y mata a las cucarachas. Entonces se dirige a Stripe, lo encañona y le dice: "Dime que no debería matarte", a lo que Stripe responde "Nada de esto es verdad, Rai". Nada de lo que hasta ahora han visto y vivido es verdad, todo es producto de una "falsa conciencia".

Pero, y aquí está el meollo de la cuestión, ¿para qué construir una máscara e implantársela a los soldados cuando la "falsa conciencia" 
puede crearse desde los aparatos ideológicos de Estado tradicionales, como demuestran los civiles que también odian y temen a las cucarachas? En la escena final de "Men Against Fire" daremos con la respuesta. En esta escena Stripe está encerrado en una celda de un blanco gélido y luminoso que la hace incluso más claustrofóbica de que lo que podría representar una celda oscura. Pero acaso el color blanco indique que el encierro no busca castigarlo sino purificarlo, recuperarlo para la lucha contra el enemigo. Arquette vuelve a aparecer en escena. Entra en la celda con dos cafés, uno para Stripe - quien no lo prueba-, que simboliza la voluntad de Arquette de mantener un encuentro y una conversación amistosa con el soldado arrestado. Stripe, sin embargo, no acepta esa cordialidad impostada. "Todo es una mentira. ¡Cucarachas! Son como nosotros". Una vez que ha descubierto que "todo es mentira" y que "las cucarachas son como nosotros" se siente engañado. La respuesta de Arquette servirá para entender la verdadera función de la máscara:

Por supuesto, lo son. Por eso mismo son peligrosas. Los humanos, ¿sabes?, tenemos mala reputación, pero somos genuinamente empáticos como especie. Quiero decir, somos realmente incapaces de matarnos entre nosotros. Lo cual es bueno. Hasta que tu futuro depende de aniquilar a tu enemigo. No sé cuánta historia estudiaste en la escuela. Hace algunos años -estoy hablando de principios del siglo XX - la mayoría de los soldados no disparaban sus armas o, si lo hacian, apuntaban por encima de la cabeza de su enemigo. Lo hacían a propósito. El ejército británico. Primera Guerra Mundial. El general paseaba por la línea con un palo y golpeaba a sus hombres para que dispararan. Incluso en la Segunda Guerra Mundial, en un tiroteo, solo un $15 \%$, $20 \%$ de los hombres apretaban el gatillo. El destino del mundo en juego y solo un $15 \%$ disparaba. ¿Qué nos dice esto? Nos dice que la guerra hubiera sido más rápida si los militares hubieran disparado a la vez. Por eso nos adaptamos. Mejor entrenamiento. Mejores condiciones. Luego vino la Guerra de Vietnam y el porcentaje de disparos aumentó hasta un $85 \%$. Volaron balas. Las muertes todavía eran bajas. Pero muchos de esos chicos que lograron matar a sus enemigos regresaron a casa traumatizados. Así eran las cosas hasta que llegó la máscara. ¿Lo ves?, la máscara... Es la más sofisticada arma militar. Te aporta datos. Para tu orientación, tus comunicaciones, tu entrenamiento. Es mucho más fácil apretar el gatillo cuando estás apuntando al hombre del saco, ¿verdad? Pero no son solo tus ojos. Cuida también el resto de 
los sentidos. No puedes oír los gritos. No puedes oler la sangre ni la mierda.

La función de la máscara no es construir un enemigo y que los soldados lo odien y lo teman y quieran aniquilarlo porque saben que su existencia puede poner en riesgo a la comunidad que defienden. Para eso no es necesaria la máscara, los aparatos ideológicos del Estado tradicionales y los mecanismos de la propaganda de guerra son suficientes para construir un enemigo, un otro deshumanizado y $\sin$ subjetividad. La función de la máscara es impedir que el enemigo pueda ser mirado y escuchado, esto es, rehumanizado y subjetivizado. Mirar al enemigo a los ojos y escuchar su historia puede generar una compasión que finalmente lleve al soldado a perdonarle la vida. La compasión constituye un peligro para la comunidad. Por eso, como dice Arquette, hay porcentajes tan altos de soldados que no dispararon sus balas en las dos guerras mundiales. El ser humano no está preparado para matar a otro ser humano, a otro igual, y mucho menos si le ve el rostro. La tecnología de guerra no tiene otra finalidad que construir una distancia entre las fuerzas contingentes. Cuanto más lejos esté el enemigo más difícil será subjetivizarlo, identificarnos con él $y$, en consecuencia, absolverlo. Por eso es más eficiente un dron que un combate cuerpo a cuerpo. La distancia es un recurso de indiferencia moral, como señala nuevamente Enzo Traverso: "La distancia hace desaparecer el temor al asesinato y hace indiferente al criminal que, como un ciego, al no percibir nada, neutraliza de este modo sus reacciones morales" (2009: 118). En este sentido, la máscara es el dispositivo definitivo en la medida en que neutraliza las reacciones morales del asesinato al construir un otro del todo irreconciliable para los soldados que han de aniquilarlo. Incluso teniéndolo delante de los ojos, la máscara produce una distancia tan grande, al borrar toda huella de humanidad y subjetividad en el enemigo, que se diluyen las implicaciones morales del acto de matar. No matan a un ser humano sino a un monstruo.

Sin embargo, una vez que el dispositivo enemigo ha generado interferencias en la máscara de Stripe, y su "falsa conciencia" se ha descubierto como efectivamente falsa, este no puede sino pronunciar, tras el parlamento de Arquette, que "ellos son seres humanos". Arquette, entonces, tiene que acudir de nuevo a la ficción inmunitaria para hacerle entender a Stripe lo necesario que es aniquilar al enemigo: 
¿Tienes idea de cuánta mierda hay en su ADN? Mayores índices de cáncer. Distrofia muscular. Menor coeficiente intelectual. Tendencias criminales. Desviaciones sexuales. Todo eso está allí. Los chequeos lo muestran. ¿Es eso lo que quieres para la próxima generación? No debes sentirte mal por hacer tu trabajo. Los aldeanos no lo harán. Los que abandonaron la lucha tampoco. Ellos no tienen la máscara. La máscara te permite hacerlo. A ti. Estás protegiendo la estirpe. Y eso, mi amigo, es un honor.

La promesa de un futuro más próspero justifica el sacrificio del presente. En su tesis VIII Sobre el concepto de Historia, Walter Benjamin (2008: 43) teorizaba acerca de la complicidad entre el progreso y el fascismo. Para el filósofo alemán, tanto el fascismo como la idea de progreso justifican los sacrificios del presente en nombre de la construcción de un futuro de prosperidad. En esta lógica, que es la que imprime el discurso de Arquette, es un honor ser un soldado, pues su cometido no es otro que salvar a la especie y garantizarle un futuro. Pero no para Stripe, desprovisto ya de la máscara y liberado del discurso construido por el poder, que no ve nada digno en mentir y matar: "No es ningún honor. Es solo matar. Mentir y matar".

\section{UNA CONCLUSIÓN DESDE LA TEORÍA DE LOS TEXTOS POSIBLES}

Ahora que Stripe conoce la verdad, qué hacer para subvertir un orden político y social que a la vez que estigmatiza al otro como sujeto irreconciliable con el sistema -al que conviene mantener a raya, o mejor: fuera de la barrera inmunitaria establecida-, somete asimismo a los miembros de la comunidad por medio de la construcción de una "falsa conciencia" que les impide conocer la verdad y, en consecuencia, actuar en libertad. En el capítulo se ofrecen dos opciones, que son las que Arquette le ofrece a Stripe: volver a ponerse la máscara, reprogramada de manera tal que olvidaría todo lo ocurrido desde que salió de cacería por primera vez, lo que le permitiría seguir creyendo que es un honor ser soldado y matar cucarachas para proteger a su comunidad, o bien vivir condenado a conocer la verdad, con la reproducción perpetua en su cabeza de las imágenes del día en que mató a un hombre, viéndolo como lo hubiera visto sin máscara, oliendo su sangre y oyendo su llanto de muerte. La "falsa conciencia", frente al dolor que implica el conocimiento de la verdad, le permitiría vivir sin sufrimiento, sin angustia $y$, sobre todo, sin arrepentimiento por los actos 
violentos en los que ha participado. Vivir con el dolor de la verdad o vivir con la serenidad de la mentira: esta es la disyuntiva a la que se enfrenta Stripe.

Sin embargo, más allá de las posibles salidas que se le abren a Stripe, a partir de este capítulo de Black Mirror podemos poner sobre la mesa otras dos posibles formas de resolución política. La primera de ellas la formula, más o menos implícitamente, el mismo episodio: la reivindicación del "derecho a narrar" desde la lógica del multiculturalismo liberal; pero, del mismo modo, el capítulo nos permite elaborar una segunda lectura, de forma crítica y aun de forma creativa, aunque esta lectura no se pueda realizar desde un entendimiento del texto como una entidad cerrada. Sin embargo, desde la "teoría de los textos posibles" (Escola, 2012), que le confiere al lector un papel participativo en la elaboración del texto, incluida la posibilidad de construir otras lecturas alternativas o complementarias, nos aventuramos a proponer otra lectura - una lectura radicalmente otrade "Men Against Fire" de Black Mirror, que opone al "derecho a narrar" que parece proponer el capítulo, el "derecho a la verdad" como una forma revolucionaria de subvertir el orden establecido. Vamos a verlo.

El capítulo, por medio de una trama en la que se muestra el carácter despótico de la deshumanización del enemigo, no ofrece sino una solución que reproduce la lógica del multiculturalismo liberal -tal y como lo describe Žižek (1997) - , en tanto celebra el reconocimiento del otro; nos invita a identificarnos con el otro y a respetar su diferencia: aunque se aleje de nuestras costumbres y de nuestros valores, seguro que será posible, con buena voluntad, integrarlas de una forma u otra en nuestra "normalidad". Se trata, en este sentido, de mirar a los ojos al otro y escuchar su historia para comprobar que, a pesar de nuestras diferencias, "ellos son como nosotros". Tras escuchar su historia, es posible asimilarlos y traducir la rivalidad antagonista en rivalidad agonística — siguiendo la terminología propuesta por Mouffe (1999)-, esto es, aceptar su diferencia bajo la condición de que esta no desestabilice la comunidad. Esta solución multicultural le otorgaría al otro el "derecho a narrar" su experiencia particular e incluso a fundar un Departamento de Roach Studies en la Universidad de la Comunidad de "Men Against Fire", pero difícilmente serviría como argumento político radical capaz de destituir un poder despótico que, a la vez que somete a 
los suyos a través de una falsa conciencia, ha pretendido aniquilar al otro siguiendo el paradigma inmunitario.

Por esta razón, frente al derecho a narrar, la única solución política y radical que podrían perseguir las cucarachas pasaría por apelar al concepto leninista de "derecho a la verdad", como lo define Žižek en Repetir Lenin (2004b: 21 y ss.). Frente a la circulación de "narrativas" que comparten el mismo rango de legitimidad (como si no hubiera una "narrativa del poder" que se impone sobre las demás), se vuelve imperativo reivindicar el carácter revolucionario que implica decir la "verdad", mostrar el funcionamiento objetivo de las relaciones de explotación y sometimiento. Esto es precisamente lo que pretenden hacer las cucarachas. No hacer escuchar su historia, sino desenmascarar las mentiras del poder. Saben que el derecho a narrar va a tener unos efectos limitados: podrán convencer a un soldado como Stripe, pero el poder pondrá en funcionamiento toda su maquinaria de guerra y propaganda - como de hecho hace Arquette en la última escena- para recuperar a Stripe para la causa. Se impone, pues, la lucha revolucionaria por medio de la "verdad". Por eso las cucarachas, cuando responden a la tecnología de guerra del enemigo con la producción de un dispositivo que introduce un virus en la máscara para desactivarla, están oponiendo la verdad de la revolución a las mentiras del poder, que son vividas, por los sujetos interpelados por su ideología, como verdaderas y como si fueran la única verdad posible, definitiva y última.

"La verdad es siempre revolucionaria", decía Gramsci (1919), en tanto respuesta a las falsedades que construye la ideología entendida como falsa conciencia. Y acaso no se trate de otra cosa: de contar la verdad frente a las ficciones que construye el poder para legitimarse y para perpetuarse. La lucha revolucionaria pasa por la construcción de una crítica de la ideología que desnude los verdaderos mecanismos del poder. En "Men Against Fire", los dispositivos que emiten luz verde para introducir un virus en la máscara operan como una reivindicación de la política de la verdad. Su artilugio sin duda recuerda al que aparece en esa película olvidada de John Carpenter - magistralmente analizada por Žižek (2012b) en su documental A Pervert's Guide to Ideology-donde su protagonista encuentra unas gafas de sol que "funcionan como gafas de crítica-de-la-ideología". A través de ellas, el protagonista puede leer el verdadero mensaje que se esconde tras la ideología, en carteles publicitarios, en la prensa, etc. Las gafas le permiten reconocer "el orden 
invisible que sostiene su apariencia de libertad", dice Žižek (2012b), sentado ante un cartel que dice "No thought", en un plano genial, filmado en blanco y negro y en la misma tonalidad con la que They live muestra la realidad real a través de las gafas. La luz verde de las cucarachas persigue el mismo objetivo revolucionario: ser una crítica de la ideología y desenmascarar la realidad construida por el poder.

Sin crítica de la ideología no hay revolución. Como nos enseña "Men Against Fire", la posibilidad revolucionaria pasa por desenmascarar esa ideología que, como una falsa conciencia, nos hace creer que vivimos en un mundo distinto al mundo real. El descubrimiento de la verdad es el único camino, o el primer paso, hacia la revolución. Para cuestionar el poder, primero hay que conocer el poder, cómo se constituye, cómo se reproduce y cómo se legitima; desnudarlo y visibilizar sus mecanismos de represión y sometimiento.

Esta es la lección radical que podemos extraer de una lectura creativa, pero asimismo posible, de "Men Against Fire". Es verdad que nosotros no tenemos ni la luz verde de las cucarachas ni las gafas de sol de They Live, pero de momento todavía no nos han despojado de algunas herramientas teóricas y críticas que, como el marxismo, operan en el desenmascaramiento del poder y en el reconocimiento de la realidad que se esconde detrás de la ideología. Todavía nos queda el derecho a la verdad como una forma de disidencia en la lucha contra el orden establecido, cuyo verdadero nombre, en el mundo real de los espectadores de Black Mirror, es capitalismo.

\section{BiBLIOGRAFÍA}

Agamben, G. (1998). Homo Sacer. Sovering Power and Bare Life. Stanford: Stanford University.

Althusser, L. (1970). La revolución teórica de Marx. México: Siglo XXI.

Althusser, L. (1971). Lenin y la filosofía. Buenos Aires: Carlos Pérez Editor.

Althusser, L. (2004). Ideología y aparatos ideológicos de Estado. En S. Žižek (comp.), Ideología: un mapa de la cuestión (pp. 115-155). Buenos Aires: FCE.

Barraycoa Martínez, J. (2012). El imaginario social del control mediático y tecnológico: la distópica Black Mirror. En C. Mateos Martín et al. (coords.), Actas IV Congreso Internacional Latina de Comunicación 
Social: Comunicación, control y resistencias (pp. 1-24). La Laguna: Universidad de La Laguna.

Becerra Mayor, D. (2013). La novela de la no-ideología. Madrid: Tierradenadie.

Becerra Mayor, D. (2015). La Guerra Civil como moda literaria. Madrid: Clave Intelectual.

Benjamin, W. (2008). Tesis sobre la Historia y otros fragmentos. México: Universidad Autónoma de la Ciudad de México.

Bourdieu, P. (1994). Raisons pratiques. París: Seuil.

Cercas, J. (2001). Soldados de Salamina. Barcelona: Tusquets.

Cigüela Sola, J., y Martínez Lucena, J. (2014a). El imaginario social de la democracia en Black Mirror. Revista Latina de Sociología, 4, 90-109.

Cigüela Sola, J., y Martínez Lucena, J. (2014b). Pensamiento pop en Black Mirror. El monstruo y el linchamiento. Doxa Comunicación, 19, 85-107.

Díaz Gandasegui Correo, V. (2014). Black Mirror: el reflejo oscuro de la sociedad de la información. Revista Teknokultura, 11(3), 583-606.

Eagleton, T. (1996). Ideología. Una introducción: Barcelona, Paidós.

Engels, F. (1974). Carta de Friedrich Engels a Franz Mehring. Londres, 14 de julio de 1893. En K. Marx y F. Engels, Obras escogidas (p. 523). Moscú: Progreso.

Escola, M. (2012). Théorie des textes possibles. Ámsterdam-Nueva York: Rodopi-CRIN.

Esposito, R. (2015). Inmunnitas. Protección y negación de la vida. Buenos Aires: Amorrortu.

Foucault, M. (1994a). Naissance de la biopolitique. En Dits et écrits, vol. 3 (pp. 818-825). Paris: Gallimard.

Foucault, M. (1994b). Les techniques de soi. En Dits et écrits, vol. 4 (pp. 783813). Paris: Gallimard.

Gramsci, A. (19 de julio de 1919). Democrazia operaia. L'ordine Nuovo. Disponible en: https://www.marxists.org/italiano/gramsci/19/democraziaoperaia.h tm

Gramsci, A. (2007). Quaderni del carcere. Torino: Einaudi, 4 vols.

Hernández-Santaolalla, V., y Hermida, A. (2016). Más allá de la distopía tecnológica: videovigilancia y activismo en Black Mirror y Mr. Robot. 
Index comunicación: Revista cientifica en el ámbito de la Comunicación Aplicada, 6(2), 53-65.

Laclau, E., y Mouffe, C. (1987). Hegemonía y estrategia socialista. Madrid: Siglo XXI.

Marx, K., y Engels, F. (1958). La ideología alemana. Montevideo: Pueblos Unidos, 1958.

"Men

Against

Fire",

Wikipedia,

https://en.wikipedia.org/wiki/Men_Against_Fire. Última consulta: 22/01/2018.

Morelli, A. (2001). Principes élémentaires de propagande de guerre. Bruselas: Labor.

Mouffe, C. (1999). Democratic Paradox. Londres: Verso.

Rodríguez, J. C. (1991). Teoría e historia de la producción ideológica. Madrid: Akal.

Traverso, E. (2009). 1914-1945. La guerre civile européenne. París: Hachette.

Žižek, S. (1997). Multiculturalism, Or, the Cultural Logic of Multinational Capitalism. New Left Review, 225, 28-51.

Žižek, S. (2004a). Ideología: un mapa de la cuestión. Buenos Aires: FCE.

Žižek, S. (2004b). Repetir Lenin. Madrid: Akal.

Žižek, S. (2012a). Primero como tragedia, después como farsa. Madrid: Akal.

Žižek, S. (2012b). Pervert's Guide to Ideology. Documental. 